\title{
Enhacing the Quality of Teachers to Meet the Requirements of Industrial Revolution 4.0 in Vietnam: Problems and Solutions
}

\author{
*Nguyen Minh Tri, Politics and National Defense Education Center, Ho Chi Minh City University of \\ Technology (HUTECH), 475A Dien Bien Phu Street, Ward 25, Binh Thanh District, Ho Chi Minh City, Vietnam, \\ nm.tri@hutech.edu.vn, ORCID:0000-0003-2535-1766 \\ Dinh The Hoang, Faculty of philosophy, University of Social Sciences and Humanities - Viet Nam National \\ University Ho Chi Minh City, dinhthehoang91@gmail.com, ORCID:0000-0001-3350-4701
}

\begin{abstract}
Facing the impact of the industrial revolution 4.0, many countries are increasingly aware that if society wants to progress, it must rely on the power of knowledge, derived from exploiting the infinite creative potential of people. Therefore, the promotion of human resources is a fundamental factor of rapid and sustainable development. The Government of Vietnam has affirmed: "Rapidly develop human resources, especially high-quality human resources, focusing on fundamental and comprehensive renovation of the national education; closely linking human resource development with the development and application of science and technology" (Communist Party of Vietnam, 2010). In order to realize the Party's policy, it is necessary to develop comprehensively and modernize education, especially to improve the quality of the faculty. Because lecturers play an important role in improving the quality of training of universities. Over the past time, the contingent of lecturers in Vietnam has been basically standardized on their professional qualifications. Most of them have masters or doctorate degrees. However, the practical knowledge and scientific research capacity of a part of lecturers are still limited, and the number of PhDs has not met the requirements of both quantity and quality. From studying the problems posed to improving the quality of faculty to meet the requirements in the context of the industrial revolution 4.0, the article proposes a number of solutions to improve the quality of faculty to meet the requirements of industrial revolution 4.0 in the coming time.
\end{abstract}

Keywords: Quality of lecturers, universities, industrial revolution 4.0, problems, solutions Received: 22.11.2020 $\quad$ Accepted: 15.12.2020 $\quad$ Published: 11.01.2021

\section{INTRODUCTION}

Entering the early years of the twenty-first century, the term industrial revolution 4.0 was widely mentioned in the media and social networks. In order to be fully aware of it, first of all, it is necessary to outline the industrial revolutions in the history of human development. Professor Klaus Schawab, President of World Economic Forum (WEF) said that: the world has undergone three industrial revolutions, they are: The first industrial revolution lasted from 1760 to about 1840 . With the catalyst being the construction of railroads and the invention of the steam engine, it paved the way for mechanical production. The Second Industrial Revolution, which began around the end of the nineteenth century to the twentieth century, opened up opportunities for mass production thanks to the introduction of electricity and assembly lines. The third industrial revolution began in 1960. It is often called the computer revolution or the digital revolution because catalysts are the development of semiconductor components, host computers (1960s), personal computer (1970s and 1980s) and the internet (1990s) (Klaus, 2018). This is the period when automated machines replace most of human functions and bring the industrial society to the information society with fast and cheap information reception and provision between businesses or internal enterprises, between production units and consumers... have become an important channel for people to conduct production and business activities as well as how people enjoy.

Referring to Industrial Revolution 4.0, Klaus Schwab said: "The fourth industrial revolution formed on the foundation of the digital revolution and incorporates many technologies is driving the unprecedented rapid transformation of the model in terms of economy, business, society and individuals. It not only changes what we are doing, the way we do it, but also who we are" (Klaus, 2018).

Since then, it can be conceived: Industrial Revolution 4.0 is the merger between the fields of technology, digital, biology, a combination of virtual and real systems, systems connected to the internet; is the development of production forces to meet the smarter needs of society. In essence, industrial revolution 4.0 is the development of a production force at its peak level in order to meet the increasingly intelligent demand for society, with the basic characteristic being the union between the fields of 
technology, digital, and biology, are the combination of virtual and real systems, systems connected to the internet. The industrial revolution 4.0 spreading around the world today is due to the fact that the speed of development and the impact of breakthroughs in technology have had unprecedented strong effects. Scientific inventions and advances are present in various fields, such as artificial intelligence, Robotics, internet of things (IoT), autonomous vehicles, biotechnology, Na-no technology, 3D printing, materials science, quantum computing... impact almost every industry at such a rapid rate that it is said the fourth industrial revolution is evolving at the rate of an exponential function.

Industrial Revolution 4.0 is expected to make a profound change in economy - society, education training. Industrial Revolution 4.0 has created opportunities and favorable conditions for people to discover new knowledge, improve the quality and scale of the economy, but there are also many challenges and risks requiring workers, managers, strategic planners to change accordingly (Dung \& Hang, 2019). In that impact, modern education, especially higher education, is one of the fields most affected because the product of training must meet the needs of the labor market, which is changing rapidly (Dung \& Hang, 2019). The strong impact of the industrial revolution 4.0 requires that universities need to completely and radically change their objectives, educational content and teaching methods (Dung \& Hang, 2019). Educational institutions will have to strongly convert to the "what the market needs" training model instead of "what our institutions have". In fact, it will have to reduce training time, training content to suit the needs of businesses, the economy and ensure learners can implement the motto "lifelong learning" (George, 2012). To do so, it is necessary to change from the central factors, in which the role and position of the teacher are there first priority.

In the era of globalization, learners will not be limited by space and time. More than ever, the In the era of globalization, learners will not be limited by space and time. More than ever, the role of the teaching staff needs a drastic change in both quality and quality. Lecturers must be professional educators with a creative mind, independent thinking, critical, capable of active cooperation, effective support for learners, and as a provider of new knowledge for learners. Therefore, focusing on improving the capacity and quality of the teaching staff, building a professional working environment, and having the best incentive mechanisms for teachers are an issue that needs special attention to improve the quality. "Teach and learn". The quality of teachers has always been considered a key factor determining the quality of education, so our country's Development Strategy for the period 2011-2020 has also affirmed that the core solution is "Developing the contingent of teachers and education managers" (Thanh \& Hien, 2019).

According to Yin Cheong Cheng, Anthony C Townsend (2000) globalization, international competition and political change have created rapid changes in the education sector in countries around the world, including Asia - Pacific. In that situation, education reform has become an urgent requirement and teachers are faced with many changes, with the expectation of taking on many tasks such as teaching, developing educational programs, course curriculum, management, professional self-improvement, selfdevelopment, helping and supporting colleagues, students and the community (Hung, 2019). In China, improving the quality of teachers and increasing autonomy for teachers are the policies that have been focused in recent years (Hung, 2019). Malaysia is a Southeast Asian country that has policies to motivate teachers, expand their roles and improve support policies. Meanwhile, Korea has recently set out the goal of training good teachers to meet the requirements of the industrial revolution 4.0, with priority given to developing teacher training programs, reforming teaching methods, improving capacity in applying information technology in teaching... (Hung, 2019)

In Vietnam, the study on the impact of the industrial revolution 4.0 on the socio-economic development in general, on the improvement of the quality of the faculty, thereby saying: Industrial revolution 4.0 is important because this revolution brings many opportunities for development and integration, but also poses many challenges for faculty in developing countries like Vietnam. Thereby, the faculty needs to increase awareness and take active actions and solutions in taking advantage of the opportunities of the industrial revolution 4.0, in order to well serve the national education and training development (Hoa, 2018).

Regarding this topic, it is said that: In the context of the industrial revolution 4.0, for language proficiency with faculty, technology-backed school management systems provide data systems that help them track the progress and progress of each classroom., promptly solve problems that arise in the learning process of students. Therefore, lecturers need to study and research to be able to take advantage of and master technology, so that these tools support and create freedom and creativity in training (Tri \& Hau 2020); At the same time, one of the highlights is the differentiation to each object of learners. Each student has different learning needs and abilities. Advances in technology allow educators to design a unique learning path that is appropriate for each specific situation. The educational software that has been put to use has the ability to adapt to each student's abilities and allow students to study at a pace 
that suits their own needs. In many countries, these adaptive learning softwares have quickly replaced part or all of the role of textbooks in the classroom (Phung, 2015).

Thus, the industrial revolution 4.0 requires the quality of the teaching staff with full of factors: the ability to adapt quickly to the working environment and to new scientific and technological advances, with the expertise and high professional qualifications; having a will to overcome difficulties, persisting at work, having professional ethics expressed through the spirit of discipline, a sense of responsibility, a spirit of democracy, cooperation and a sense of community; have teamwork skills, ability to change, quickly adapt, have high integration, have breakthrough initiatives, creativity at work; have real capacity to create high results and excel at work, have competitive capacity.

In fact, no matter how much science and technology develops, it cannot completely replace the role of the teaching staff. Over the past time, the teaching staffs in Vietnam have been basically standardized on their professional qualifications, and most of them have masters or doctorate degrees. However, the practical knowledge and scientific research capacity of a part of lecturers are still limited, and the number of PhDs has not met the requirements of both quantity and quality. Especially, with the current development of science and technology, learners can completely learn knowledge and skills through the Internet. Therefore, lecturers must always cultivate and improve their professional qualifications, knowledge and skills to confirm the leading role of lecturers. The article focuses on analyzing the problems posed by the teaching staff in the industrial revolution 4.0 and proposing some solutions to improve the quality of lecturers to meet the requirements of the industrial revolution 4.0.

\section{RESULTS}

\section{Issues posed to the teaching staff in the industrial revolution 4.0}

The Industrial Revolution 4.0 has created a huge change in life, economy and society. In the future, machines will perform $42 \%$ of office hours by 2022 , compared with $29 \%$ now (Bao, 2020). And although 75 million jobs will be replaced by machines, 133 million new jobs will appear (George, 2020). Digital technologies are becoming a driver of change in higher education, impacting all areas from teaching and learning to school-related activities, especially for teaching staff.

Lecturers in universities are among the forces affected by the industrial revolution 4.0 and face various challenges caused by rapid and varied changes in the environment. According to Mehaffy, these changes can be divided into domain subjects: people (learners, teachers, sponsors, managers), university model, course model, data and analyzing learning, cost, measuring success, and threats to acceptability (George, 2012). For the nations in the world in general and Vietnam in particular, applying the achievements of the industrial revolution 4.0 to improve the quality of training, promote building a learning society and lifelong learning is the trend of today's education. The application of industrial revolution 4.0 to training in the education system in Vietnam has had previous policies, plans and roadmaps, but there are still many special problems, especially for the teaching staff.

Firstly, the application of industrial revolution 4.0 will reduce lectures, impart knowledge to develop learners' capacity, increase self-study ability, create learning opportunities anytime, anywhere, humanizing learning, contributing to creating a learning society and lifelong learning. The explosion of technology platforms IoT, Big Data, AI, SMAC (social network - mobile - big data analysis- cloud computing) is forming digital education infrastructure. Industrial Revolution 4.0 focuses on two main contents: digital transformation in educational management and digital transformation in teaching, learning, testing, evaluation, and scientific research (Nam, 2020).

Currently, a number of universities in Vietnam have built new teaching models such as online training without classrooms, no need for classroom teachers, and learners will be guided online learning. Virtual classes, virtual teachers, simulated virtual devices, lectures are digitized and shared through platforms such as Facebook, YouTube, Grab, Uber... are applied in career training. Since then, knowledge cannot be narrow and exclusive by one person or within an organization. Learners have many opportunities to access, accumulate, refine the new, the good, have more opportunities to become a global citizen - future workers with the ability to work in a creative environment and competitive.

Since then, the training schools in Vietnam will build training programs and content in the direction of "what the market needs" and the contents of the basic subjects will have to be shortened and replaced with the content which is necessary to meet the needs of businesses, the economy in general and ensure learners can implement the motto "lifelong learning". According to this new model, the connection between educational institutions and enterprises is an inevitable requirement to complement each other.

At the same time, to promote the formation of training facilities in enterprises to divide common resources, making resources to be used in a more optimal way. This will affect the arrangement of administrators, service providers and teachers of vocational education institutions. At that time, at 
educational institutions, all student data from codes, scores, personal information... were digitized in one storage place. In many cases, teachers only need to "throw" documents on "cloud" (Cloud) and everyone argues on "cloud" while still ensuring privacy, efficiency and synchronization. Before this reality, if schools don't change, there will be no learners. What needs do businesses in particular and the market in general has, the more learners will aim to find places to meet that demand. This is really a challenge because most schools today just stop at the level of teachers teaching with projectors, videos, sharing documents online. The tight budget is also one of the main points that makes science and technology applications undeveloped in schools.

The main changes have posed challenges of the Education sector in training human resources according to the new needs of the times. If teachers only focus on providing and transmitting knowledge according to traditional methods, in the digital age, robots and smart devices will do better than the role of the teacher. Facing the challenges and requirements that the 4.0 industrial revolution poses to education, the role of the faculty has changed drastically, transforming from the traditional role of imparting knowledge to the role of catalyzing and coordinating, shifting to a learner-centered, learnercentered function in the teaching process. Instead of providing one-way knowledge, lecturers should make the most of the means to stimulate students to actively study and deepen research. Therefore, lecturers need to be braver and braver, constantly update new knowledge about both expertise and science and technology, strengthen scientific research activities, and cooperate with teamwork to catch up with current trend of development and international integration today.

In addition, students may have difficulty in selecting and using resources. Due to the "open", multidimensional, plentiful resource, both are able to help students. Students can make good use of the documents, but also make it difficult for students to choose their materials when studying. There are many unofficial and uncensored resources on the internet, making it difficult for students and students to identify scientific and correct documents that have been censored when used. Therefore, they need clear guidance and direction from teachers.

Secondly, according to statistics, the number of internet users in Vietnam as of January 2020 reached 68.17 million, accounting for $70 \%$ of the population, of which 65 million were using social networks and more than 145.8 million connection to mobile data networks in Vietnam (Cleversim, 2020). Despite a large number of Internet users and social networks, mobile access to the Internet has increased significantly in recent years, but the use of technology for educational purposes is not high, especially in higher education, so when entering the higher education environment, students often take time to perfect their skills in using cyberspace. On the other side, not all instructors have the capacity and confidence to use digital tools to support teaching. Digital transformation in higher education is known that the application of services, technology and digital by universities, helps improve learning outcomes, increases equity and increases efficiency, but this effect is only truly sustainable when both the learner and the teacher are well trained in how to master the use of technical means to achieve educational goals.

Thirdly, in the age of Internet connection, knowledge becomes too vast, information is too rich, and machines become more intelligent and can even teach people. Teaching and learning in the era of industrial revolution 4.0 becomes very different from previous generations. Lecturers cannot reconnect existing knowledge just through a few keywords about the subject's content in the Google search engine. Students can quickly search for a variety of free shared printed book documents; fully capable students absorb more knowledge than what lecturers convey in class. Therefore, lecturers in the era of industrial revolution 4.0 will be more evocative and oriented than imparting knowledge. In addition, the learning space is no longer confined to the classroom framework, replacing physical schools with lecture halls, libraries and fixed timetables, online classes in the industrial revolution. 4.0 can take place anywhere, at any time. Online training is one of the ways of teaching organization of the higher education 4.0 model, the trend of global higher education integration, and the soul of online training based on IT application platform.

Fourthly, the training program in Vietnam is not yet flexible, and the content is not in line with the needs and trends of the industrial revolution 4.0 labor market. Education and training is one of the changing fields. The vocational education system will be strongly and comprehensively affected. The list of training occupations and training programs will have to be adjusted and updated continuously because boundaries between fields are very fragile. Universities provide training in two directions, on the one hand to meet the requirements of socio-economic development in the country. On the other hand, training provides human resources to meet the requirements of the labor market in the context of international integration. However, the pressure on university faculty is even greater when the training program meets both high expertise in a certain field and interdisciplinarity (information technology, digital, networking, specialized knowledge) and other indispensable skills, such as: the ability to think systematically, the ability to synthesize, the ability to connect between the real and virtual worlds, 
creativity, teamwork skills, the possibility of interdisciplinary cooperation...

In addition, online training forms require teachers not to impart knowledge anymore, but to instruct and coordinate creating a learning environment for students; not teaching but focusing on helping students orient their learning. Teachers not only have to be good at their expertise, are willing to answer students' questions, but also must have bravery, regularly improve their capacity to adapt to new circumstances, especially in time to innovate teaching methods, IT applications maximization and visual means in the teaching process.

Fifthly, the industrial revolution 4.0 is taking place strongly and affecting each individual, business and especially the higher education environment - where directly training human resources to serve the foundation. Industry 4.0. In the near future, when ASEAN becomes a borderless market, the free flow of labor moves from other Southeast Asian countries to Vietnam, Vietnamese enterprises will have more choices in terms of human resources. But the Vietnamese manpower is at risk of losing at a home court. Meanwhile, the universities themselves and the training decisions will not fulfill their social mission. Even without innovation motivation, universities risk being acquired and acquired once the education market has certain openings. That is the story of the survival strategy of universities in the next one or two years, because as a part of the economy, universities are not immune to competition.

This model is a relatively new concept in the current Vietnamese education system. However, with the drastic changes in the socio-economy, it is necessary to apply this model to the Vietnamese tertiary curriculum. An innovative university model aimed at innovating and increasing Vietnam's higher education, contributing to improving the teaching quality of faculty in the context of the industrial revolution 4.0; increasing the ability to connect with businesses, transfer technology, attracting investment, forming links between universities and businesses; enhancing international integration so that Vietnam's education sector will quickly reach regional and international standards in training.

Thus, to meet the requirements of the industrial revolution 4.0, higher education institutions need to constantly improve the quality of the faculty. Universities need to foster and improve the quality of their faculty by many different measures.

\section{Proposing a number of solutions to improve the quality of the faculty to meet the requirements of industrial revolution 4.0}

Firstly, to improve the professional qualifications of the faculty.

In the digital revolution, universities need to step up the work of enhancing professional qualifications for their faculty. The professional training for teachers should combine advanced training models 4.0, online and distance training so that lecturers can improve their professional qualifications and new approach teaching models. There are a number of models of online teaching that have been and will be applied in higher education, such as: the E-learning model (the network management system model); B-learning model (teaching model combining classroom learning with collaborative learning via computer network and self-study); Conferencing technology application model is a service that allows many people to conference remotely, with the appearance of images and sounds from one person to the other; Higher education model 4.0 (digital university model) is an intelligent education model and the main link between school elements - managers - entrepreneurs, bringing advancement of information technology into schools to improve training efficiency that makes teaching and learning happen anytime, anywhere. The university based on education standards in the context of the industrial revolution 4.0 is not only a place for training and research, but also a center of innovation, promoting entrepreneurship among students, improving labor productivity to meet Vietnam's development needs. The work of fostering and improving the quality of the school's teaching staff will not be highly effective if each lecturer does not make efforts to overcome difficulties to strive in their work. Therefore, each lecturer needs to regularly self-foster, constantly learn to improve knowledge, cultivate political bravery, professional ethics, and teacher style. In the current integration trend, teachers need to have a solid knowledge base, deep understanding, a firm grasp of the system of teaching methods and be flexible in applying; have skills of applied research, ability to use modern teaching facilities, electronic lectures in teaching; pedagogical skills, especially teachers need skills to inspire learners.

Secondly, improve the capacity to use technological facilities for the teaching process for the teaching staff.

Industrial Revolution 4.0 is the "digital revolution", so teachers must be capable of managing network resources, capable of using technological facilities proficiently to serve the teaching process. To get these competencies, universities need to focus on fostering the ability to use technology facilities to serve the teaching process by opening short-term training courses or organizing exchanges and sharing sessions of lecturers with skills to apply information technology effectively in teaching for lecturers who are weak in computer skills. This work should be conducted regularly and continuously focusing on the 
following contents: how to digitize lectures, teaching materials, upload them to the electronic library for easy access by students, easy control by lecturers, new updates every year; how to design online classes, build learning forums, academic exchanges on the Internet; training in using electronic libraries, exploiting endless resources on the Internet for teaching purposes.

In addition, in order to facilitate the development of this capacity of faculty members, the school needs to publish technology tips that teachers can use to support the teaching process. When teachers manage and understand the available technology facilities, they will be more proactive and creative in applying technology and allow and guide their students to use them to improve learning process.

Thirdly, enhace the foreign language skills of the teaching staff.

To access advanced scientific and technological knowledge brought about by the development of the industrial revolution 4.0, teachers cannot help but be fluent in foreign languages. This is a necessary condition for lecturers to integrate with the trend of globalization and integration with world higher education. Therefore, universities need to focus on promoting teachers to meet foreign language standards and always improve foreign language proficiency for teachers. At the same time, the school needs to create more conditions to help teachers improve their foreign language skills, such as enhancing academic activities in English, teaching specialized modules in English for both teachers and students to have ability to study their major in English; introduce and train teachers on how to write articles, how to contact and submit articles in international seminars and magazines according to each specialty in English. The increase in sending lecturers to study and research abroad is also an important measure to improve foreign language skills for lecturers.

Fourthly, promote the work of fostering scientific research capacity for the faculty.

In addition to fostering professional competencies, lecturers need to constantly foster their scientific research competencies because scientific teaching and research are two main and complementary tasks. A lecturer with good professional qualifications will be a solid foundation to promote scientific research capacity to develop. On the contrary, lecturers with good scientific research capacity will discover many new and advanced things in terms of content and methods for teaching. Through scientific research, lecturers' thinking abilities have also been trained and strengthened.

In the digital age, people always have to explore, discover and adapt to the unpredictable changes brought about by the development of technology. Therefore, the trend of research-oriented training has been suggested by many experts. To train research-oriented, teachers must firstly be scientific research experts to train human resources with strong scientific research capacity and creativity.

For these necessary reasons, the training of scientific research capacity for faculty should be carried out by universities regularly and continuously with measures such as: Linking scientific research with content innovation, teaching methods and educational practices; combining professional training with scientific research by strengthening the strategy of training faculty towards research; building specialized research groups to enhance the exchange of academic, scientific research skills; organize and encourage lecturers to participate in scientific conferences and seminars at home and abroad to exchange experiences in scientific research.

Universities need to attach importance to quality over the number of published articles, step by step build and complete the process of evaluating, verifying, and accepting scientific research projects to ensure the quality of public progress more and more. In order to improve the quality of articles and scientific research topics, schools should encourage the formation of research groups to enhance academic exchanges and experience initiatives in scientific research. Higher education institutions should have policies to support faculty funding in these activities to encourage them. If possible, schools should have appropriate rewards for scientific works with high applicability and articles published in prestigious international journals. It is also a way of empowering the school. teaching.

Fifthly, the school expanded cooperation, fostering cooperation and sharing experiences in

In the current trend of information technology integration and development, each lecturer must always self-study to update the achievements of educational science research as well as the applications of science, technology, and communication into teaching; assess students' learning outcomes according to competency-based approaches; curriculum development. In order to fulfill the above requirements, the training and capacity building for the faculty have become extremely important. Today, the development of faculty is not the sole task of a lecturer or a certain school, and the trend of teacher training is to cooperate and share experiences with each other. In order for faculty cooperation to be effective, universities need to actively link, create networks, regularly create professional exchange forums, with the participation of a large number of lecturers in different professional positions. In the forum, lecturers should share teaching and educational experiences that teachers have applied with high efficiency. Cooperation in retraining is an effective job for improving the professional capacity of each 
faculty member. This job aims to enhance teachers' integration skills, fostering their own professional expertise. Because in the end, each lecturer needs to cooperate to improve their professional capabilities as well as build their own professional skills. A dynamic, creative and effective education school.

Sixthly, well implement policies for faculty.

Universities based on annual revenues need to build a mechanism and remuneration policy for the university teaching staff that is commensurate with their individual achievements and abilities; adjust salary policies, preferential allowances, remuneration mechanisms to improve the material and spiritual life, create motivation and conditions for university teaching staff to improve their capacity and qualifications. When life is guaranteed, the teachers can be assured of their career and improve the quality of education. Schools should create funding to support teaching staff; especially young lecturers who have a lot of contributions to the school's activities, carrying out and publishing many quality scientific research projects but with very low salaries due to lack of seniority. Remuneration for teachers at schools should be based on actual assessment of qualifications, capabilities, job positions, career contributions and performance of each lecturer.

\section{CONCLUSIONS}

The quality of universities begins with the quality of the faculty. In the context of the ongoing industrial revolution 4.0, each lecturer, in addition to regularly fostering professional competencies, teaching and scientific research capabilities, also requires a focus on fostering a number of competencies to meet new requirements that is the ability to use proficient technology media, proficiency in foreign languagesin communication and teaching. Therefore, universities must always pay attention to and invest in training and fostering competencies for faculty, to meet the needs of learners in the new era. By doing this, our universities can keep up with advanced universities in the world and the region, and meet the requirements of the 4.0 industrial revolution era.

\section{CONFLICTS OF INTEREST}

The author(s) declare(s) that there is no conflict of interest regarding the publication of this article

\section{REFERENCES}

Bao, H. T. (2020). Digital transformation in the time of COVID-19, 2020. Retrieved from https://tiasang.com.vn/khoa-hoc-cong-nghe/Chuyen-doi-so-thoi-Covid19-23135.

Cleversim. (2020). Industry 4.0: Definition, Design Principles, Challenges, and the Future of Employment. Retrieved from https://www.cleverism.com/industry-4-0/.

Communist Party of Vietnam. (2011). Document of the 11th National Delegation. Hanoi, Vietnam: National politics, 106.

Dung, T. Q., \& Hang, P. T. (2019). The fourth industrial revolution and the impact on teaching methods at present university, Journal of Education, vol. 2, 94-97.

George, M. (2012). Challenge and Change, 2012. Retrieved from https://er.educause.edu/articles/2012/9/challenge-and-change.

Hoa, T.V.T. (2017). Industrial Revolution 4.0 - Issues for socio-economic development and international integration of Vietnam. Hanoi, Vietnam: National Political Publishing House, 154-158.

Hung, T. M. (2019). The impact of the 4.0 revolution on Vietnam's education. Retrieved from http://tapchicongthuong.vn/bai-viet/tac-dongcua-cuoc-cach-mang-40-toi-giao-duc-cuavietnam-27238.htm?print=print.

Klaus, S. (2018). Fourth Industrial Revolution (Ministry of Foreign Affairs and Proofreading). Hanoi, Vietnam: National Political Publishing House, 20, 14-15.

Nam, H. H. (2020). Digital transformation in the field of education and training: Situation and solutions. Hanoi, Vietnam: National Political Publishing House, 85-87.

Phung, X.N. (2015). Vietnam Education in the context of the fourth industrial revolution, 2015. Retrieved from http://vinhuni.edu.vn/van-ban/seo/giao-duc-viet-nam-trong-boi-canh-cuoc-cach-mangcong-nghiep-lan-thu-tu-86324.

Thanh, T. V., \& Hien, N. N. (2019). Improving the quality of teacher training to meet the requirements of educational innovation and industrial revolution 4.0. Retrieved from http://vinhuni.edu.vn/daotao/seo/nang-caochat-luong-dao-tao-giao-vien-dap-ung-yeucau-doi-moi-giao-duc-va-cachmang-congnghiep-40-86558.

Tri, N.M. (2019). Vietnamese education in the context of the Fourth Industrial Revolution. Vietnam Social 
Science Journal, No. 8, 25-37.

Tri, N.M., \& Hau, D.T. (2020). Impact of industrial revolution 4.0 on education and training in Ho Chi Minh City, Vietnam. Journal of Critical Reviews, Vol 7 (12), 2708 - 2713. http://doi: 10.31838/jcr.07.12.413. 